\title{
THE ANTIBIOTICS RESISTANCE AND THE PRESCRIPTIONS' PATTERN FOR URINARY TRACT INFECTIONS AT KING FAHAD SPECIALIST HOSPITAL
}

\author{
NORAH RA LNQER ${ }^{1}$, AREEJ AL JASSER ${ }^{2}$, MUGAHID A. MOBARK ${ }^{1 *}$
}

${ }^{1}$ Department of Pharmacy Practice, College of Pharmacy, Qassim University, Buraydah 51452, KSA. ${ }^{2}$ Clinical Pharmacy, King Fahad Specialist Hospital, Buraydah, KSA. Email: Mu.mohammed@qu.edu.sa

Received: 17 March 2020, Revised and Accepted: 19 April 2020

\section{ABSTRACT}

Objectives: Urinary tract infection (UTI) is one of the diseases with a highest prevalence in the world. This study evaluated the antibiotics resistant and the prescription pattern for UTI with the aim to participate as an effective monitoring study that enhances rational antibiotics' prescription.

Methods: We conducted a retrospective cross-sectional study at King Fahad Specialist Hospital from May 2018 to January 2019 . We included a total of 306 patients with UTI. 204 patients diagnosed clinically and empirically treated (Group A), 102 patients underwent urine for culture and sensitivity tests (Group B).

Results: UTI showed higher occurrence in female in both Groups A (61\%) and B (65\%). The mean age was higher in Group B (55.8 years) than Group A (39.44 years). The most commonly prescribed antibiotics for UTI were Trimethoprim + Sulfamethoxazole (TMP+SMX) (56\%) and ciprofloxacin (15\%). Escherichia coli was the most commonly isolated organism (36.3\%) followed by Klebsiella pneumonia (30\%). Although $41.17 \%$ of organisms were sensitive to TMP+SMX, 38.2\% were resistant to it. The organisms were sensitive to amikacin in $80.4 \%$ and to gentamicin in $61.8 \%$ whereas, $61.8 \%$ were resistant to ampicillin. Luckily, no resistance was reported neither for nitrofurantoin nor for vancomycin.

Conclusion: The study showed significant resistance to the commonly prescribed TMP+SMX and ciprofloxacin compared to absolute sensitivity to the less prescribed nitrofurantoin. This necessitates special consideration for local susceptibility in empirical therapy.

Keywords: Antibiotic, Prescription, Resistance, Urinary tract infection.

(C) 2020 The Authors. Published by Innovare Academic Sciences Pvt Ltd. This is an open access article under the CC BY license (http://creativecommons. org/licenses/by/4. 0/) DOI: http://dx.doi.org/10.22159/ajpcr.2020.v13i7.37486

\section{INTRODUCTION}

Urinary tract infection (UTI) is one of the diseases with a highest prevalence in the world. It commonly affects female than male and more than $50 \%$ of all women were affected with UTI during their lifetime $[1,2]$. UTI is commonly bacterial in origin and mainly caused by Gram-negative bacteria, especially Escherichia coli. Other causative bacteria include Klebsiella pneumonia, Proteus mirabilis, Pseudomonas aeruginosa, Enterobacter species, Enterococcus species, Group B Streptococcus, and Staphylococcus saprophyticus $[3,4]$.

UTI can easily be treated with different regimens of antibiotics with varying efficacy, tolerability, and cost. The treatment is commonly started before the culture and susceptibility test results [5]. However, the massive and inappropriate use of antibiotics has led to increased antimicrobial resistance that strongly necessitates knowledge about antimicrobial susceptibility pattern. This study evaluated and compared the antibiotic susceptibility pattern to prescription pattern in patients with UTI attending at King Fahad Specialist Hospital.

\section{METHODS}

A retrospective cross-sectional, hospital-based study was conducted at King Fahad Specialist Hospital in the period from May 2018 to January 2019. The study was approved by the Regional Research Ethics Committee-Qassim Province, under the registration number 1441-524299. We included a total of 306 UTI patients in this study. We categorized them into two groups; 204 patients were clinically diagnosed with UTI and empirically treated with antibiotics (Group A), the remaining 102 patients were diagnosed based on urine culture and sensitivity tests (Group B). The urine specimens after processing were incubated at a temperature of $35 \pm 2^{\circ} \mathrm{C}$ on CLED agar for 24-48 h. The isolates of bacterial colony were identified and a count $\geq 100,000$ colony-forming units per milliliter of urine was considered positive. The antimicrobial susceptibility was determined using the disk diffusion method. We constructed two data collection forms; one designed for Group (A) and it included patients' demographic characteristics, the diagnosis, the antibiotics prescribed, their doses, frequency, and duration. The other was designed for Group (B) and it included patients' demographic characteristics, the type of bacteria that were isolated, the antibiotics sensitivity, and resistance results. The data were analyzed by Statistical Package for the Social Sciences (SPSS) version 23. We used descriptive statistics for the analysis of demographic data of patients, antibiotics prescription, bacteria isolated, and the sensitivity and resistance patterns of organisms to antibiotics. Chi-squared test was used for the association among categorical variables and $p>0.05$ was considered significant.

\section{RESULTS}

The demographic characteristics of the study population UTI was common (62.1\%) in female in both studied groups representing $(60.8 \%)$ in Group A and $(64.7 \%)$ in Group B. In Group A, the UTI was higher in age group 19-36 years $(47.5 \%, n=97)$ with a mean age of 38.9 year, while in Group (B), the UTI was higher among age group of $55-72$ years $(43.1 \%, n=44)$ with a mean age of 55.83 year. In both groups, UTI was less in patients aged $1-18$ years $(5.5 \%)$ and in those more than 72 years (8.8\%). The disease was mainly distributed among patients aged 19-72 years (Table 1 ).

\section{The pattern of antibiotics prescription}

A total of 224 antibiotics were empirically prescribed for 204 patients. Trimethoprim + Sulfamethoxazole (TMP+SMX) was the most commonly prescribed antibiotics (56\%, $\mathrm{n}=126)$ in a dose of $960 \mathrm{mg}$ and a mean duration of 5.1 days then followed by ciprofloxacin $(15 \%, \mathrm{n}=33)$ in a dose of $500 \mathrm{mg}$ with mean duration of 6.2 days and cefuroxime axetil 
Table 1: Age and gender distribution of urinary tract infections' patients $(n=306)$

\begin{tabular}{|c|c|c|c|c|c|c|c|c|c|}
\hline \multirow[t]{3}{*}{ Age groups } & \multicolumn{3}{|l|}{ Group (A) } & \multicolumn{3}{|l|}{ Group (B) } & \multicolumn{3}{|c|}{ Total Group A and B } \\
\hline & \multicolumn{2}{|l|}{ Gender } & \multirow{2}{*}{$\begin{array}{l}\text { Total \% } \\
\text { (n) }\end{array}$} & \multicolumn{2}{|l|}{ Gender } & \multirow{2}{*}{$\begin{array}{l}\text { Total \% } \\
\text { (n) }\end{array}$} & \multicolumn{2}{|l|}{ Gender } & \multirow[t]{2}{*}{ Total \% (n) } \\
\hline & Male \% (n) & Female \% (n) & & Male \% (n) & Female \% (n) & & Male \% (n) & Female \% (n) & \\
\hline $1-18$ years & $1.9(4)$ & $4.4(9)$ & $6.4(13)$ & $1.9(2)$ & $1.9(2)$ & $3.9(4)$ & $1.9(6)$ & $3.6(11)$ & $5.5(17)$ \\
\hline $19-36$ years & $20(41)$ & $27.4(56)$ & $47.5(97)$ & $2.9(3)$ & $13.7(14)$ & 16.7 (17) & $14.4(44)$ & $22.9(70)$ & 37.3 (114) \\
\hline $37-54$ years & $8.3(17)$ & 19.1 (39) & $27.4(56)$ & $8.8(9)$ & $13.7(14)$ & $22.5(23)$ & $8.5(26)$ & $17.3(53)$ & $25.8(79)$ \\
\hline $55-72$ years & $3.9(8)$ & $8.3(17)$ & $12.3(25)$ & 16.7 (17) & $26.5(27)$ & $43.1(44)$ & $8.1(25)$ & $14.4(44)$ & $22.5(69)$ \\
\hline Total & $39.2(80)$ & $60.8(124)$ & $100(204)$ & $35.3(36)$ & $64.7(66)$ & $100(102)$ & $37.9(116)$ & $62.1(190)$ & $100(306)$ \\
\hline
\end{tabular}

Table 2: The antibiotics prescribed for urinary tract infection $(n=204)$

\begin{tabular}{|c|c|c|c|}
\hline The antibiotics prescribed & Frequency \% (n) & Dose in mg (frequency) & Mean of duration (days) \\
\hline TMP-SMX* & $56(126)$ & $960 \mathrm{mg}(126)$ & 5.1 \\
\hline \multirow[t]{2}{*}{ Ciprofloxacin } & $15(33)$ & $500 \mathrm{mg}(29)$ & 6.2 \\
\hline & & $250 \mathrm{mg}(4)$ & \\
\hline \multirow[t]{2}{*}{ Cefuroxime axetil } & $11(24)$ & $500 \mathrm{mg}(20)$ & 5.5 \\
\hline & & $250 \mathrm{mg}(4)$ & \\
\hline \multirow[t]{2}{*}{ Amoxicillin clavulanic acid } & $4(9)$ & $1000 \mathrm{mg}(5)$ & 6 \\
\hline & & $625 \mathrm{mg}(4)$ & \\
\hline \multirow[t]{2}{*}{ Amoxicillin } & $2(4)$ & $500 \mathrm{mg}(3)$ & 5 \\
\hline & & $250 \mathrm{mg}(1)$ & \\
\hline \multirow[t]{2}{*}{ Levofloxacin } & $1(2)$ & $750 \mathrm{mg}(1)$ & 12 \\
\hline & & $250 \mathrm{mg}(1)$ & \\
\hline Nitrofurantoin & $1.3(3)$ & $100 \mathrm{mg}(3)$ & 7 \\
\hline \multirow[t]{2}{*}{ Ceftriaxone } & $4(10)$ & $2000 \mathrm{mg}(5)$ & 3.5 \\
\hline & & $1000 \mathrm{mg}(5)$ & \\
\hline Doxycycline & $1(2)$ & $100 \mathrm{mg}(2)$ & 10 \\
\hline Metronidazole & $1(3)$ & $500 \mathrm{mg}(3)$ & 5 \\
\hline \multirow[t]{2}{*}{ Tazocin } & $1(2)$ & $2250 \mathrm{mg}(1)$ & 3 \\
\hline & & $4500 \mathrm{mg}(1)$ & \\
\hline Cefepime & $0.4(1)$ & $1000 \mathrm{mg}(1)$ & 7 \\
\hline \multirow[t]{2}{*}{ Azithromycin } & $2(5)$ & $500 \mathrm{mg}(3)$ & 3 \\
\hline & & $1000 \mathrm{mg}(2)$ & \\
\hline Total & $100.0(224)$ & - & - \\
\hline
\end{tabular}

*TMP/SMX: Trimethoprim/sulfamethoxazole

Table 3: The organisms isolated in urine culture correlated with gender $(n=102)$

\begin{tabular}{llll}
\hline Organism & \multicolumn{2}{c}{ Gender } & \multirow{2}{*}{ Total \% (n) } \\
\cline { 2 - 3 } & $\begin{array}{l}\text { Male \% } \\
\text { (n) }\end{array}$ & $\begin{array}{l}\text { Female \% } \\
\text { (n) }\end{array}$ \\
\hline Escherichia coli & $8.8(9)$ & $27.5(28)$ & $36.3(37)$ \\
Providencia spp. & $0(0)$ & $1(1)$ & $1(1)$ \\
Klebsiella pneumonia & $7.8(8)$ & $21.6(22)$ & $29.4(30)$ \\
Pseudomonas aeruginosa & $6.9(7)$ & $2(2)$ & $8.8(9)$ \\
Enterococcus faecalis & $4.9(5)$ & $5.9(6)$ & $10.8(11)$ \\
Staphylococcus aureus & $1(1)$ & $0(0)$ & $1(1)$ \\
Staphylococcus epidermidis & $2(2)$ & $0(0)$ & $2(2)$ \\
Enterobacter aerogenes & $0(0)$ & $2(2)$ & $2(2)$ \\
Enterobacter cloacae & $2(2)$ & $2(2)$ & $3.9(4)$ \\
Proteus mirabilis & $1(1)$ & $2.9(3)$ & $3.9(4)$ \\
Streptococcus & $1(1)$ & $0(0)$ & $1(1)$ \\
Total & $35.3(36)$ & $64.7(66)$ & $100(102)$ \\
\hline
\end{tabular}

p-value $=0.029<0.05$ we accept the null hypothesis at alpha=0.05. Hence, there is association between the type of organisms and gender at significant level 0.05

$(11 \%, \mathrm{n}=24)$ while the least frequency was observed in cefepime $(0.4 \%$, $\mathrm{n}=1$ ) (Table 2). In most of the patients (90.2\%), only one antibiotic was empirically prescribed for the treatment of UTI and in few cases $(9.3 \%)$ two antibiotics were prescribed and only one patient received three types of antibiotics $(0.5 \%)$
The antibiotics' sensitivity and resistance pattern

The findings in the urine culture and sensitivity tests of Group B patients showed that $E$. coli was the most commonly isolated organism $(36.3 \%$, $\mathrm{n}=37)$, followed by K. pneumonia (29.4\%, n=30), Enterococcus faecalis $(10.8 \%, \mathrm{n}=11)$, and P. aeruginosa $(8.8 \%, \mathrm{n}=9)$ while Streptococcus, Providencia spp., and Staphylococcus aureus were the least isolated organisms. There was significant association between the type of organisms isolated and the gender as $\mathrm{p}=0.029$ (Table 3). An $80.4 \%$ of the organisms isolated were sensitive to amikacin, followed by meropenem (79.4\%), imipenem (78.4\%), and gentamicin (61.8\%). While, the resistant to ampicillin was detected in $61.8 \%$, followed by ciprofloxacin $(48 \%)$ and only $1 \%$ resistance to tigecycline was reported. Although, $41.2 \%$ of the organisms were sensitivity to TMP+SMX, $38.2 \%$ of them were resistant to it. Intermediated sensitivity was seen in gentamicin (5.9\%), ciprofloxacin (4.9\%), tigecycline (4.9\%), cefuroxime (3.9\%), imipenem $(2.9 \%)$, and amikacin $(2 \%)$. No resistance was reported neither for nitrofurantoin nor for vancomycin in the tested patients (Table 4).

\section{DISCUSSION}

This cross-sectional, hospital-based study showed that UTI was more common (62.1\%) in female in both studied Groups A and B. UTI still higher in female until the age group $55-72$ years $(14.4 \%$ in female and $8.1 \%$ in male); however, it was more in male than female in patients aged more than 72 years. In study done by Salem et al. reported more occurrence of UTIs in female (67.6\%) than in male (32.4\%) [6]. Foxman also reported that the prevalence of UTI is higher in women than men 
Table 4: The antibiotics sensitivity and resistance patterns in isolated organisms

\begin{tabular}{|c|c|c|c|c|}
\hline Antibiotics tested & Sensitive \% (n) & Resistant \% (n) & Intermediate \% (n) & Not tested \% (n) \\
\hline Ampicillin & $22.5(23)$ & $61.8(63)$ & $0(0)$ & $15.7(16)$ \\
\hline Cefuroxime & $31.4(32)$ & $40.2(41)$ & $3.9(4)$ & $24.5(25)$ \\
\hline Ceftazidime & $43.1(44)$ & $42.2(43)$ & $0(0)$ & $14.7(15)$ \\
\hline Gentamicin & $61.8(63)$ & $18.6(19)$ & $5.9(6)$ & $13.7(14)$ \\
\hline Amikacin & $80.4(82)$ & $2.9(3)$ & $2.0(2)$ & $14.7(15)$ \\
\hline Imipenem & $78.4(80)$ & $2.9(3)$ & $2.9(3)$ & $15.7(16)$ \\
\hline Meropenem & $79.4(81)$ & $4.9(5)$ & $0(0)$ & $15.7(16)$ \\
\hline Cefepime & $42.2(43)$ & $41.2(42)$ & $0(0)$ & $16.7(17)$ \\
\hline Tazocin & $33.3(34)$ & $23.5(24)$ & $1(1)$ & $42.5(43)$ \\
\hline TMP-SMX * & $41.2(42)$ & $38.2(39)$ & $0(0)$ & $20.6(21)$ \\
\hline Tetracycline & $30.4(31)$ & $36.3(37)$ & $0(0)$ & $33.3(34)$ \\
\hline Amoxicillin + clavulanate & $32.4(33)$ & $42.2(43)$ & $2.9(3)$ & $22.5(23)$ \\
\hline Ciprofloxacin & $45.1(46)$ & $48(49)$ & $4.9(5)$ & $2(2)$ \\
\hline Cefotaxime & $33.3(34)$ & 38.2 (39) & $0(0)$ & 28.4 (29) \\
\hline Tigecycline & 56.9 (58) & $1(1)$ & $4.9(5)$ & $37.3(38)$ \\
\hline
\end{tabular}

*TMP/SMX: Trimethoprim/sulfamethoxazole

and it still higher even at the age of 60 years [7]. Furthermore, Keyhan et al. reported a higher incidence of UTIs in patients aged 36-65 years in female, while in male it was most frequency in age $<65$ years old [8].

In this study, we noticed that among patients in Group A the UTI was common $(47.5 \%)$ in young adult (19-36 years) with a mean age of 38.9 years, while in Group B it was common (43.1\%) among the elderly (55-72 years) with a mean age of 55.8 years, reflecting the possibility of resistance and high recurrence rate at this age group which justify the need for culture and sensitivity tests. In general, in both studied groups, there was less occurrence of UTIs at the extremities of age; in younger aged patients (1-18 years) (5.5\%) and patients more than 72 years $(8.8 \%)$.

In this study, sulfamethoxazole+ trimethoprim (960 mg) twice daily was the most antibiotic prescribed as empirical antibiotics (56\%), followed by ciprofloxacin (15\%), cefuroxime axetil (11\%), amoxicillin clavulanic acid (4\%), and ceftriaxone (4\%). Inversely, we noticed a different result reported by Mohamed et al. as they found that the most antibiotics prescribed empirically were amoxicillin (28\%), followed by ciprofloxacin (11\%), and co-amoxiclav (10\%). As reported in international survey on the antimicrobial resistance of microorganisms causing UTI, there is a wide variability across countries in bacterial susceptibility rates to the antimicrobials [9], so the empirical antibiotic therapy should consider the local susceptibility patterns of uropathogens.

This study showed that most of physician prescribed only one type of antibiotic $(n=184,90.2 \%)$ for the treatment of UTI. There are only few cases where two antibiotics were prescribed $(n=18,9.3 \%)$ and only one patient received three types of antibiotics $(0.5 \%)$. These findings largely agreed with the guideline for empirical treatment of UTIs $[10,11]$.

In Group B patients, the urine culture results showed that E. coli was the most commonly isolated organism (36.3\%), followed by K. pneumonia (29.4\%), E. faecalis $(10.8 \%)$, P. aeruginosa $(8.8 \%)$, and P. mirabilis (3.9\%), while, Streptococcus (1\%), providencia spp. (1\%), and staphylococcus aureus (1\%) were the least. In study done by Cunha et al., showed a highest frequency of E. coli (60.4\%) and followed by Klebsiella spp. (14.2\%) (3). Furthermore, Wong et al. study found out that the most common pathogen isolated was E. coli (75.9\%) [12].

We compared the type of organism isolated with the patients' age and gender and we concluded that there was no association with age as $\mathrm{p}=0.17$. In contrast, there was significant association with gender as $\mathrm{p}=0.029$ and we consider $\mathrm{p}$ value significant at $<0.05$.

In Group B patients, the organisms isolated were highly sensitive to amikacin (80.4\%), followed by meropenem (79.4\%), imipenem
(78.4), and gentamicin (61.8\%), while TMP/SMX although it showed $(41.2 \%)$ sensitivity, the resistance was significantly high (38.2\%). Luckily, the organisms were found to be absolute sensitive and no reported resistance in all tested cases for nitrofurantoin (10 cases) and vancomycin (14 cases). The organisms were highly resistant to ampicillin (61.8\%), followed by ciprofloxacin (48\%), piperacillin (42\%), and less resistance to tigecycline (1\%); however, there was intermediated effect to gentamicin (5.9\%). We observed that there is a significant resistance among the commonly empirically prescribed antibiotics (TMP/SMX and ciprofloxacin) while no reported resistance among the less prescribed one (nitrofurantoin) which reflects overuse among empirical prescription of antibiotics and necessitate special consideration for local susceptibility patterns when prescribing the antibiotics empirically for UTI patients. In Cunha et al. study, they found that aminoglycosides, nitrofurantoin, and third-generation cephalosporins were highly susceptible over (90\%) while TMP-SMX and quinolones reported highly resistance [3].

\section{CONCLUSION}

The study of UTI at KFSH showed UTIs pattern aligned with international studies as UTI was most common in female and commonly caused by $E$. coli. However, significant resistance to the highly empirically prescribed TMP+SMX and ciprofloxacin was noted, beside absolute sensitivity to nitrofurantoin which should be considered in the empirical therapy for UTI with regard to the local susceptibility pattern.

\section{AUTHORS' CONTRIBUTIONS}

1. Norah R. A Lnqer; collect data, managed the analyses of the study and wrote the first draft of the manuscript.

2. Areej AL Jasser; managed the literature searches and interpreted the data

3. Mugahid A. Mobark; designed the study, performed the statistical analysis, and wrote the protocol.

This manuscript has been read and approved by all the authors, and the requirements for authorship have been met, and we believe that this manuscript represents honest work.

\section{CONFLICTS OF INTEREST}

No any conflicts of interest to disclose.

\section{AUTHORS FUNDING}

No any source of support for the authors to disclose and all the works are supported by the authors. 


\section{REFERENCES}

1. Michno M, Sydor A. Urinary tract infections in adults. Przegl Lek 2016;73:504-8.

2. Gugliotta G, Calagna G, Adile G, Polito S, Saitta S, Speciale P, et al. Is intravesical instillation of hyaluronic acid and chondroitin sulfate useful in preventing recurrent bacterial cystitis? A multicenter case control analysis. Taiwan J Obstet Gynecol 2015;54:537-40.

3. Cunha MA, Assunção GL, Medeiros IM, Freitas MR. Antibiotic resistance patterns of urinary tract infections in a Northeastern Brazilian capital. Rev Inst Med Trop São Paulo 2016;58:2. Available from: http://www.scielo.br/scielo.php?script=sci_arttext\&pid=s0036$46652016005000201 \& \operatorname{lng}=\mathrm{en} \& \operatorname{tlng}=\mathrm{en}$.

4. Cullen IM, Manecksha RP, McCullagh E, Ahmad S, O'Kelly F, Flynn RJ, et al. The changing pattern of antimicrobial resistance within 42033 Escherichia coli isolates from nosocomial, community and urology patient-specific urinary tract infections, Dublin, 1999-2009. BJU Int 2012;109:1198-206.

5. Rocha JL, Tuon FF, Johnson JR. Sex, drugs, bugs, and age: Rational selection of empirical therapy for outpatient urinary tract infection in an era of extensive antimicrobial resistance. Braz J Infect Dis 2012;16:115-21.

6. Salem MM, Magdy M, Alhosiny IM. Distribution of classes 1 and 2 integrons among multi drug resistant $E$. coli isolated from hospitalized patients with urinary tract infection in Cairo, Egypt. Aust J Basic Appl Sci 2010;4:398-407.
7. Foxman B. The epidemiology of urinary tract infection. Nat Rev Urol 2010;7:653.

8. Keyhan H, Sedighi S, Mashayekhi B, Fathi M, Mokhtari M. Community acquired urinary tract infections' etiological organisms and antibiotics susceptibility patterns. Nephrourol Mon 2017;9:e62146. Available from: http://www.numonthly.com/en/articles/62146.html.

9. Schito GC, Naber KG, Botto H, Palou J, Mazzei T, Gualco L, et al. The ARESC study: An international survey on the antimicrobial resistance of pathogens involved in uncomplicated urinary tract infections. Int J Antimicrob Agents 2009;34:407-13. Available from: https://www. linkinghub.elsevier.com/retrieve/pii/S0924857909002143.

10. Grover ML, Bracamonte JD, Kanodia AK, Bryan MJ, Donahue SP, Warner AM, et al. Assessing adherence to evidence-based guidelines for the diagnosis and management of uncomplicated urinary tract infection. Mayo Clin Proc 2007;82:181-5. Available from: https://www. linkinghub.elsevier.com/retrieve/pii/S0025619611609968

11. Gupta K, Hooton TM, Naber KG, Wullt B, Colgan R, Miller LG, et al. International clinical practice guidelines for the treatment of acute uncomplicated cystitis and pyelonephritis in women: A 2010 update by the infectious diseases society of America and the European society for microbiology and infectious diseases. Clin Infect Dis 2011;52:e103-20.

12. Wong CK, Kung K, Au-Doung PL, Ip M, Lee N, Fung A, et al. Correction: Antibiotic resistance rates and physician antibiotic prescription patterns of uncomplicated urinary tract infections in Southern Chinese primary care. PLoS One 2018;13:e0192466. 